\title{
David Nicol. Middleton and Rowley: Forms of Collaboration in the Jacobean Playbouse. Toronto: University of Toronto Press, 2012. Pp. xii, 216.
}

HEATHER HIRSCHFELD

The University of Tennessee, Knoxville
Early Theatre 17.1 (2014), 221-224

DOI: http://dx.doi.org/10.12745/et.17.1.16

In the opening pages of his inventive, persuasive, and nuanced contribution to scholarship on collaborative enterprises, David Nicol briskly surveys a range of current approaches to the phenomenon of joint work in the Renaissance playhouse. Having distinguished between scholars who subscribe to the persistence of recognizable authorial hands in collaborative plays (but who champion instances when those hands are subsumed to a single vision) and scholars who insist - based either on the material conditions of the Renaissance theatre or on theoretical challenges to the singular author - that the individual dramatist is an anachronism, Nicol proposes an alternative approach, a fresh, rewarding hermeneutic that grounds his compelling readings of Middleton's and Rowley's joint work. His methods in Middleton \& Rowley: Forms of Collaboration in the Jacobean Playhouse acknowledge and even embrace the existence of distinct authorial contributions in order to put interpretive pressure on the moments when those contributions come into ideological or stylistic conflict. As he explains, his goal is to 'read collaborative texts for their disunities' and to focus on how various 'positions of playwrights (and other agents) can create friction within a text' $(32,13)$.

Nicol is interested, in other words, in the difference that the differences between Middleton and Rowley (as well as other theatrical personnel) make. $\mathrm{He}$ is especially attuned to these differences because he has so thoroughly immersed himself in each of these playwrights' oeuvres, not only in their joint work but in the plays for which there is significant evidence of sole authorship (for these attributions, as well as for the division of collaborative plays, Nicol relies heavily on the seminal studies of MacDonald P. Jackson and David Lake as well as more recent assessments by Gary Taylor). This immersion, and the sharp intertextual observation it enables, informs the entire book, even as it branches out to include 'forms of collaboration' other than writing shared by playwrights.

Nicol's work on The Changeling (1622), the most canonical of the plays he discusses, is especially enlightening. He studies the play across two chapters: 
first, in his introduction as a 'test case' for his methodology, and then again in chapter one, where he isolates the playwrights' competing theological perspectives and suggests their effects on dramatic characterization. Although this organization results in some repetitiveness, it is highly effective in establishing, against a tide of Middleton-focused criticism, Rowley's significance in the partnership. Nicol explains in his opening discussion that the playwrights - whose relationship he claims was more business-like than friendly — pursued a 'framing' system for their collaborative plots, a structure that, as he continues in the following chapter, resists the 'fusi[on]' of Middleton and Rowley 'into a transcendental singular author' (37). So although most critics have celebrated the play's apparent seamlessness of thematic and linguistic design, Nicol focuses instead on The Changeling's discontinuities of characterization, particularly in terms of the simultaneously chivalric and insipid Alsemero. According to Nicol, such differences are fueled by the 'profound dissimilarity in the writers' representation of the process by which sin is conceived and enacted', dissimilarities which map roughly onto traditional (Rowley) and Calvinist (Middleton) soteriologies. Taking up Reformation doctrine is a bold tactic — not the usual recourse for students of collaboration and attribution - and it is reinforced by persuasive readings of Rowley's All's Lost by Lust (1618-20) in comparison with Middleton's Revenger's Tragedy (1606) and supplemented by an effective sampling of Thomistic as well as contemporary theological writings on the nature of reason, will, grace, and sin. The real payoff is in the reading of The Changeling, which notes the competing strains in representation — strains that match traditional attributions to Middleton and Rowley - between characters who 'choos[e] to commit evil or [are] essentially damned from the start' (53). This 'conflict between two attitudes to moral change' is at the heart of the play's 'discordance' and thus its psychological and theatrical complexity (63).

Such theatrical complexity is explored from a different angle in Nicol's chapter on Wit at Several Weapons (1613-15), which considers the effects of the theatre's material contexts on the scene of joint writing. Drawing from recent scholarship on the celebrity of the early modern player, Nicol demonstrates the ways in which Rowley's 'distinctive stage persona had great significance for the results of Rowley's collaborations with Middleton' (66). He thoroughly surveys the development of Rowley's clown persona, which Nicol identifies as the 'guileless', 'plain-speaking' clown whose artlessness posed dramaturgic challenges to collaboration with the more ironic Middleton. Those challenges were met in Wit, in which the playwrights 'found a way 
to use Rowley's persona within a satire', turning him into a 'sensitive clown' whose sentimentality 'collided' with Middleton's cynical satire to produce 'potentially thrilling theatre' (91).

The remaining two chapters are also concerned with the ways in which the material conditions of the stage influence or contribute to joint work. Chapter 3, on A Fair Quarrel (1616), is inspired in its intention to locate the play in the context of a company's repertory and that repertory's ideological appeal. Nicol's reading of the play's conflicting generic sensibilities is (if a little too reliant on the seminal but by now dated work on city comedy by Walter Cohen and Lawrence Manley) deft and commanding, suggesting that the play's formal 'hybridity' was the result of the two authors working 'in their specialist areas for a company [Prince Charles's Men] that was in a transitional phase between the public and private theatres' (93). One could quibble with the idea of the company's 'transitional phase', since it was performing in public theatres until 1619 (though Nicol may be nodding to the company's recent incorporation with a boy troupe or to contemporary acknowledgment that indoor performances were gaining hold of the playing landscape). But the attention to company repertories and audience expectations adds effectively to Nicol's case for inclusive definitions of collaborative work, including one in which 'the playing company becomes a kind of author figure' (113).

His discussion in the final chapter of other kinds of 'authorial presences' - non-clown actors and patrons 'who shaped what the playwrights could or could not do' - however, may be seen to strain this inclusivity at least to, if not past, the breaking point (124). The chapter begins with a striking account of an unnamed but gifted boy actor who, Nicol suggests, likely played the roles of both Pretiosa in The Spanish Gypsy (1623) and Isabella in The Changeling and in whom the audience would have delighted. It continues by turning to The Old Law (1618-9), arguing that the play - whose plot involves the proposed euthanizing of men over eighty years old and women over sixty - represents the highlight of a program of politically ambitious dramas performed by Prince Charles's Men which encode its patron's (cautious) antagonism towards his father King James. As an allegorical reading of the play, this is smart and cogent. But to claim that 'whether Prince Charles or his father had any influence over its content or not, their presences must have been felt by the authors and by the audience, and thus can be thought of as collaborators of a kind', threatens to empty out the meaning of 'collaboration' so that any kind of influence on a play's construction, or any kind of recognition of topicality by an audience, fits the category (138). Certainly 
this perspective on collaboration has been suggested in other venues; in a recent formulation Gordon McMullan suggests that because 'collaboration is the paradigmatic mode of textual production', a 'narrow sense' of joint work individual authors working together — is 'finally inseparable' from a 'broad sense' of collaboration which includes writers, companies, printers, compositors, and proofreaders as well as institutions like patronage and discursive logics such as genre. ${ }^{1}$ But Nicol has worked so hard to establish the lines and significances of the 'separable' that the claim for the collaborative force of patronage is less persuasive than his discussions of joint work between writers, actors, and companies. Perhaps it is the inclusive end toward which the argument had been inexorably building; I would rather have seen him consider the role of Rowley in Middleton's blockbuster A Game at Chess (1624) from his compelling methodological perspective. He is more convincing when he returns, in a kind of epilogue, to discuss the echoes in The Spanish Gypsy of other lines written for the clown Rowley.

Indeed, one of the most impressive aspects of this book is the fresh attention it gives to Rowley as a crucial force not only in the Middleton-Rowley collaborations but in the world of the early modern theatre as a total company man: actor, playwright, sharer. Nicol's careful work in the annals of theatre history serves him especially well in bringing Rowley's persona and place to life as part of the rich terrain of non-King's Men's plays for the Jacobean stage. For these reasons, as well as its attention to details of theatrical performance and its illuminating readings of multiple plays, Nicol's book is an important contribution to the study of early modern authorship and collaboration.

\section{Notes}

1 Gordon McMullan, “'Our Whole Life is Like a Play”: Collaboration and the Problem of Editing', Textus: English Studies in Italy 9.2 (1996), 437-60. 